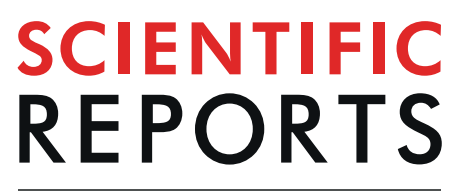

natureresearch

\title{
Nuclear receptor CAR-ER $\alpha$ signaling regulates the estrogen sulfotransferase gene in the liver
}

\author{
MyeongJin Yi, Muluneh Fashe, Shingo Arakawa, Rick Moore, Tatsuya Sueyoshi \& \\ Masahiko Negishi*
}

Estrogen sulfotransferase (SULT1E1) inactivates estrogen and regulates its metabolic homeostats. Whereas SULT1E1 is expressed low in the liver of adult mice, it is induced by phenobarbital (PB) treatment or spontaneously in diabetic livers via nuclear receptors. Utilizing constitutive active/ androstane receptor (CAR) KO, estrogen receptor $\alpha$ (ER $\alpha$ KO, phosphorylation-blocked ER $\alpha$ S216A $\mathrm{KI}$ mice, it is now demonstrated that, after being activated by PB, CAR binds and recruits ER $\alpha$ onto the Sulte1 promoter for subsequent phosphorylation at Ser216. This phosphorylation tightens CAR interacting with ER $\alpha$ and to activates the promoter. Hepatic SULT1E1 mRNA levels are constitutively up-regulated in type 1 diabetic Akita mice; CAR spontaneously accumulates in the nucleus and activates the Sult1e1 promoter by recruiting phosphorylated ER $\alpha$ in the liver as observed with PB-induced livers. Thus, this CAR-phosphorylated ER $\alpha$ signaling enables these two nuclear receptors to communicate, activating the Sult1e1 gene in response to either PB or diabetes in mice. ER $\alpha$ phosphorylation may integrate CAR into estrogen actions, providing insights into understanding drug-hormone interactions in clinical therapy.

Estrogens are known to regulate hepatic metabolism and metabolic syndrome besides profound actions in basic biology and disease developments ${ }^{1-3}$. Estrogen is inactivated by sulfation; estrogen sulfotransferase SULT1E1, a member of the cytosolic sulfotransferase superfamily, is the major enzyme that specifically and effectively sulfates estrogen $^{4-9}$. SULT1E1 is expressed low in the liver of normal adult mice but is induced by treatment with therapeutic drugs such as phenobarbital (PB). Nuclear receptor CAR (NR1I3) mediates this induction by activating the Sult1e1 gene ${ }^{10}$. In addition, SULT1E1 expression is spontaneously up-regulated in the liver of diabetic mice ${ }^{11}$. The molecular mechanism of this spontaneous activation of the Sult1e1 gene remains unknown. Ablation of the Sult1 gene affected on diabetic phenotypes in mice, demonstrating that SULT1E1 plays a role in regulating hepatic metabolic syndrome ${ }^{12}$. Here, it was examined whether estrogen receptor $\alpha(E R \alpha)$ regulates the Sult1e1 gene and whether CAR plays a role in this regulation in diabetic livers. In either induced or spontaneous activation of the Sult1e1 gene, the molecular mechanism by which CAR and ER $\alpha$ communicate to activate the gene may be conserved.

CAR was found to repress gluconeogenic genes in mouse livers, providing mechanistic insights into understanding the improvement of hepatic insulin sensitivity and the decrease of blood glucose levels in PB-treated epileptic patients ${ }^{13}$. CAR is inactivated by phosphorylation at Thr38 within the DNA binding domain (DBD) ${ }^{14}$. $\mathrm{PB}$ and insulin antagonize each other to regulate CAR activation through this phosphorylation ${ }^{15}$. PB stimulates dephosphorylation to activate CAR, whereas insulin represses it to inactivate CAR ${ }^{16}$. Therefore, phosphorylation of CAR is the intersection where drugs and hormones can interfere with each other's actions. Thr38 of CAR directs its sidechain towards a surface of the ligand-binding domain (LBD), but not towards an interface with $\mathrm{DNA}^{17,18}$. This residue regulates both intra- and inter-molecular interactions; phosphorylation of T38 prevents CAR from forming intra-molecular interactions between the DBD and LBD and enables CAR to homodimerize, while dephosphorylation leads to CAR monomers, allowing it to heterodimerize with RXR $\alpha$ (NR2B1). CAR utilizes two different surfaces located on opposite sides of the CAR molecule to form either homodimer or heterodimer. The presence of two dimer interfaces can confer the CAR of the CAR-RXR $\alpha$ heterodimer capability of interacting with an additional nuclear receptor. A recent study shows that such an interaction may occur with

Pharmacogenetics Section, Reproductive and Developmental Biology Laboratory, National Institute of Environmental Health Sciences, National Institutes of Health, Research Triangle Park, North Carolina, 27709, USA. *email: negishi@niehs.nih.gov 
(a)

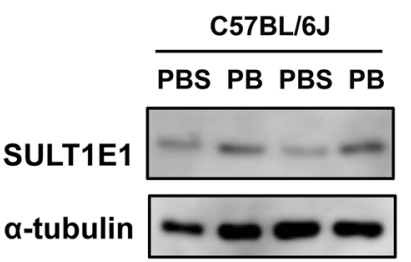

(b)

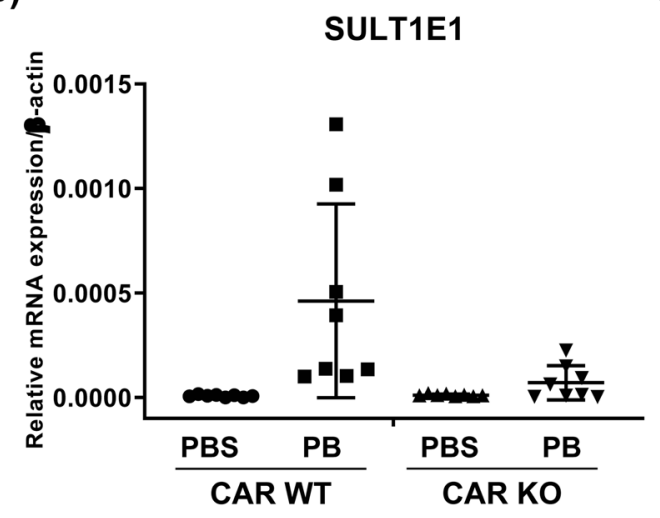

(c)

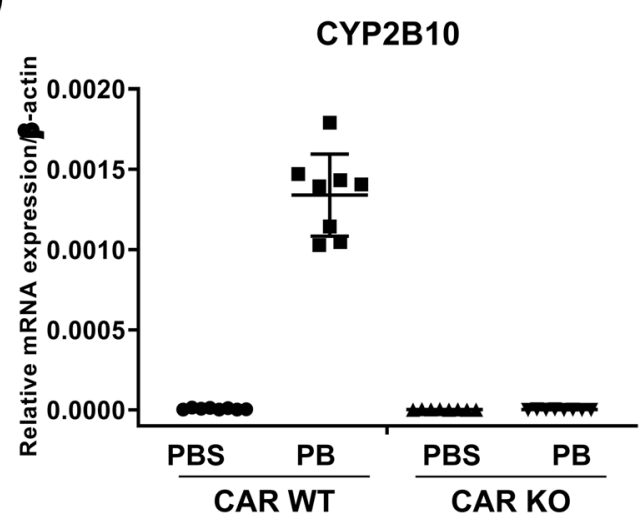

Figure 1. PB-induced expression of SULT1E1 in CAR WT and CAR KO males. (a) Cytosolic extracts were prepared from C57BL/6J male livers which were treated with PB or PBS. SULT1E1 was induced by PBtreatment, and a polyclonal antibody for $\alpha$-tubulin was used as a loading control. (b) PB induction of SULT1E1 mRNA in CAR wild-type and KO mouse livers treated with PBS or PB $(N=8)$. $P$-value derived from ANOVA is 0.0013. (c) Hepatic RNAs were prepared from CAR WT $(N=8)$ and CAR KO $(N=8)$ males treated with PB or PBS for $24 \mathrm{~h}$. The same RNAs used for SULT1E1 were utilized to measure the levels of CYP2B10 mRNA. All $p$-values for four different groups are lower than 0.0001. All data are presented as means \pm S.D. of values of individual mice, and one-way ANOVA was used as a statistical analysis for multiple groups.

ROR $\alpha$ (NR1F1) in mouse livers ${ }^{19}$. Two dimer interfaces provide CAR with a structural basis to diversify its interactions with other nuclear receptors which may include ER $\alpha$, and phosphorylation allows CAR to regulate these interactions ${ }^{16}$.

When ER $\alpha$, CAR or SULT1E1 was ablated in mice, their livers developed similar metabolic disorders and affected on diabetic phenotypes ${ }^{11,20,21}$, suggesting that the Sult1e1 gene may be a common target of CAR and ER $\alpha$, thus these two nuclear receptors may directly interact to regulate the gene. Because the sequence around Thr38 is a conserved phosphorylation motif among most of mouse and human nuclear receptors ${ }^{16}$, regulation by this motif could be extended to many other nuclear receptors. In fact, when CAR interacted with ROR $\alpha$ to activate the Sult1e1 gene, ROR $\alpha$ was phosphorylated at Ser100, the corresponding residue within the $\mathrm{DBD}^{19}$. The same motif is conserved in ER $\alpha$ of human (Ser212) and mouse (Ser216) ${ }^{22,23}$. Therefore, it is possible that CAR interacts with ER $\alpha$ through its phosphorylation at Ser216 to activate the Sult1e1 gene may undergo the same regulation.

Here, we examined CAR-ER $\alpha$ signaling as a mechanism that integrates signals to activate the Sult1e1 gene in PB-induced as well as diabetic livers. We utilized ER $\alpha$ S216A KI and ex3-ER $\alpha$ KO mice to investigate phosphorylation of Ser216, CAR KO mice to determine the role of CAR in the interaction with phosphorylated ER $\alpha$ and, diabetic Akita and $o b / o b$ mice to examine SULT1E1 expression in diabetic livers. A phospho-Ser216 peptide antibody was used to detect phosphorylation of ER $\alpha$ at Ser216. Real-time PCR determined SULT1E1 mRNA levels and chromatin immunoprecipitation assays examined bindings of nuclear receptors to the Sult1e1 promoter. Interactions and complex formation of nuclear receptors were examined by gel-shift and co-immunoprecipitation assays. First, the mechanism of this CAR-ER $\alpha$ signaling was determined in PB-treated mouse livers and subsequently, examined in diabetic livers. Here, experiments that establish CAR-ER $\alpha$ signaling will be presented and implication of this signal in diabetes will be discussed. Current findings with phosphorylation of the conserved motif should be extended to investigate nuclear receptor communication far beyond CAR.

\section{Results}

PB induction of SULT1E1 in mouse livers. Cytosolic fractions were separately prepared from livers of two male mice treated with PBS or PB for $24 \mathrm{~h}$ and subjected to western blot analysis. SULT1E1 protein levels were increased after PB treatment in both samples (Fig. 1a and Supplement Fig. 1). Liver RNAs were prepared from CAR WT and CAR KO males treated with PBS or PB for $24 \mathrm{~h}$ and subjected to real time PCR analysis. SULT1E1 mRNAs were detected low in PBS-treated livers (Fig. 1b). While PB treatment increased hepatic SULT1E1 mRNA about 58-fold in CAR WT males, this increase was profoundly diminished in CAR KO males (Fig. 1b). Confirming well-known observations ${ }^{24}$, CYP2B10 mRNA was induced in CAR WT over 180-fold but not CAR $\mathrm{KO}$ males (Fig. 1c). These observations indicated that CAR activates the Sult1e1 gene in response to PB. On the 
(a)

(c)
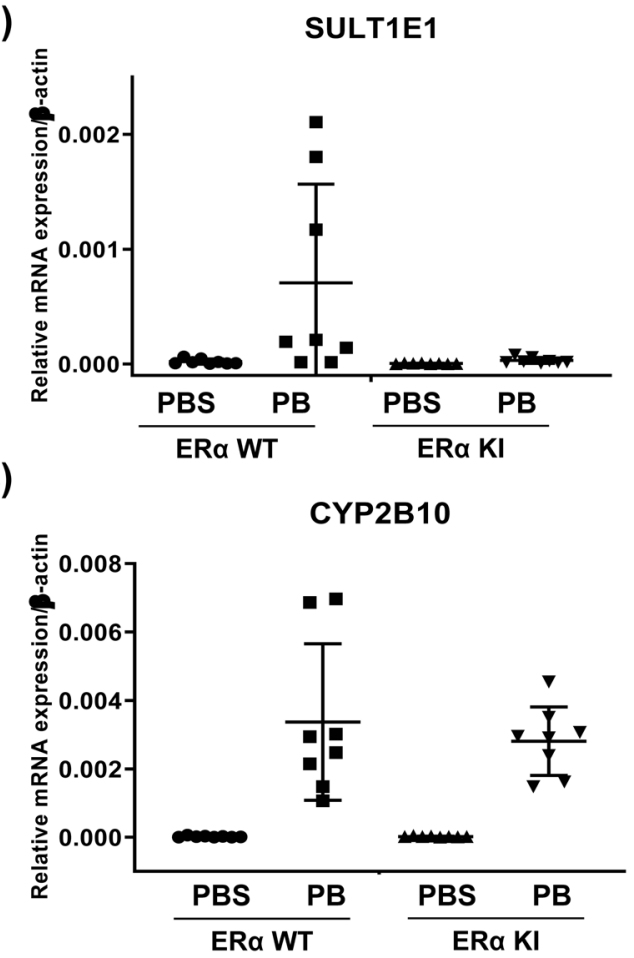

(b)

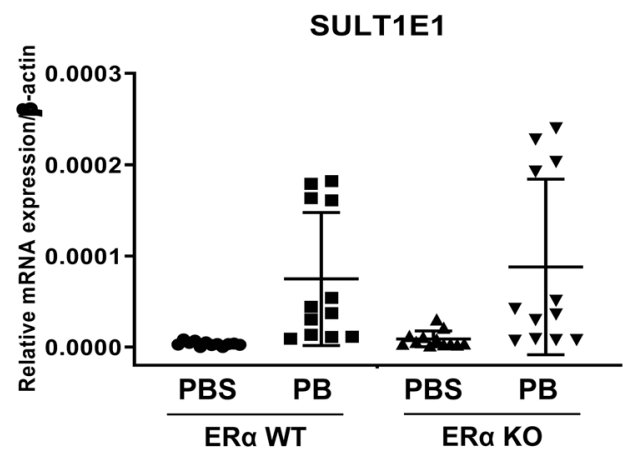

(d)

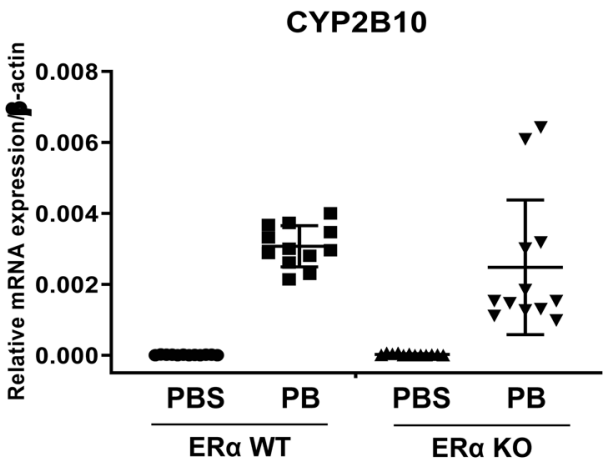

Figure 2. PB-induced expression of SULT1E1 mRNA in ER $\alpha$ S216A KI and ER $\alpha \mathrm{KO}$ males. Hepatic RNAs were prepared from $(\mathbf{a}) \mathrm{ER} \alpha \mathrm{WT}(N=8)$, and $\mathrm{ER} \alpha \mathrm{S} 216 \mathrm{~A} \mathrm{KI}(N=8)$, males or $(\mathbf{b}) \mathrm{ER} \alpha \mathrm{WT}(N=12)$ and ER $\alpha$ KO $(N=12)$ males treated with PB or PBS for $24 \mathrm{~h}$, to measure each SULT1E1 mRNA. Each $p$-value of both data set is derived from as 0.0059 , and $<0.0001$, respectively. The same RNA samples from (c) ER $\alpha \mathrm{WT}(N=8)$, and $\mathrm{ER} \alpha \mathrm{S} 216 \mathrm{~A} \mathrm{KI}(N=8)$, males or $(\mathbf{d}) \mathrm{ER} \alpha \mathrm{WT}(N=12)$ and $\mathrm{ER} \alpha \mathrm{KO}(N=12)$ males were used to measure CYP2B10 mRNA. The both $p$-values of data are estimated as lower than 0.0001 . All data are presented as means \pm S.D. of values of individual mice. One-way ANOVA was used as a statistical analysis for data set of ER $\alpha$ S216A KI, and Kruskal-Wallis test was used to analyze the data set of ER $\alpha \mathrm{KO}$.

other hand, higher residual levels of SULT1E1 mRNA in PB-treated CAR KO compared with that of CYP2B10 mRNA also suggested the presence of an additional factor that regulates the Sult1e1 gene in the absence of CAR.

SULT1E1 expressions in ER $\alpha \mathrm{KI}$ and KO males. $\mathrm{ER} \alpha \mathrm{WT}$ and $\mathrm{ER} \alpha \mathrm{S} 216 \mathrm{~A}$ KI male mice were treated with PBS or PB, and RNAs were prepared for real time PCR analysis (Fig. 2a). SULT1E1 mRNA levels were increased about 33-fold by PB treatment in ER $\alpha$ WT males, whereas this increase was severely repressed in the $\mathrm{ER} \alpha \mathrm{S} 216 \mathrm{~A}$ KI males. These observations suggested that ER $\alpha$ might be phosphorylated at Ser216 when ER $\alpha$ is present to activate the Sult1e1 gene. Unexpectedly, SULT1E1 mRNA was equally induced in ER $\alpha$ WT and ER $\alpha$ KO males (Fig. 2b), suggesting that PB-activated CAR can initiate SULT1E1 transcription in the absence of ER $\alpha$. In contrast to SULT1E1, CYP2B10 mRNA was induced over 155-fold and 125-fold by PB in ER $\alpha$ S216A KI and KO males, respectively (Fig. 2c,d), demonstrating that ER $\alpha$ was not involved in PB induction of the Cyp2b10 gene.

Phosphorylated ER $\alpha$ binding the Sult1e1 promoter. Chromatins were prepared from the liver of male mice treated with PBS or PB for subsequent chromatin immunoprecipitation (ChIP) assays. For this assay, a $236 \mathrm{bp}(-168 /+68)$ sequence within the proximal promoter was amplified (Fig. 3a). We found increased ER $\alpha$ binding to the Sult1e1 promoter, and ER $\alpha$ appeared to be bound to the promoter following PB treatment. It was phosphorylated at Ser216 in CAR WT males; this binding and phosphorylation was not observed in CAR KO males (Fig. 3b-d, and Supplement Fig. 2a). On the other hand, ER $\alpha$ bound the promoter but was not phosphorylated at Ser216 in ER $\alpha$ S216A KI males (Fig. 3e-g, and Supplement Fig. 2b). These observations first demonstrated the high specificity of this $\alpha$ P-S216 antibody to phosphorylated ER $\alpha$ at Ser216 in ChIP assays. Moreover, the finding with CAR KO males indicated that CAR is required for ER $\alpha$ to bind the promoter and for subsequent phosphorylation; ER $\alpha$ binds the promoter first and then, subsequently, is phosphorylated at Ser216.

ACAR-phosphorylated ER $\alpha$ complex on the promoter. The DR4 within the 263 bp sequence of the promoter (Fig. 4a) was used for gel shift assays with nuclear extracts prepared from the liver of CAR WT and CAR KO males treated with PBS or PB (Fig. 4b). PB treatment profoundly increased a disappeared band in the extract from CAR WT males. A corresponding band was neither detected nor increased in that from CAR KO males. This band formation was inhibited by adding an anti-CAR or an $\alpha$ P-S216 antibody to reaction mixtures. These observations suggested that a complex containing both CAR and phosphorylated ER $\alpha$ binds the DR4 
(a)

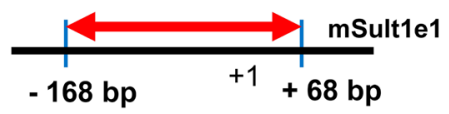

(b)

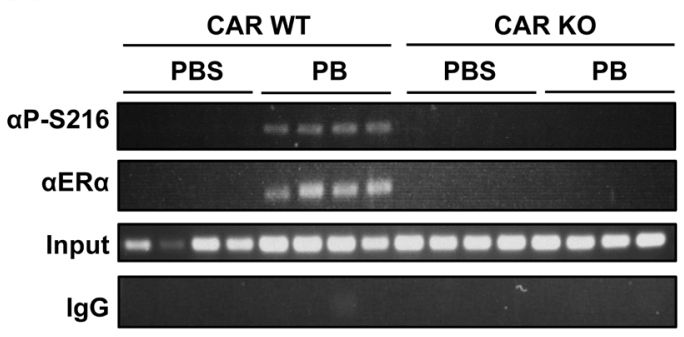

(c)

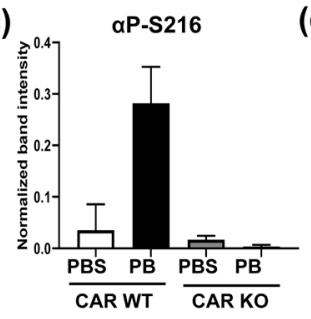

(d)

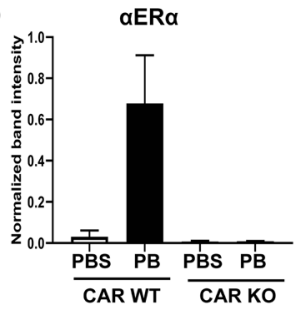

(e)

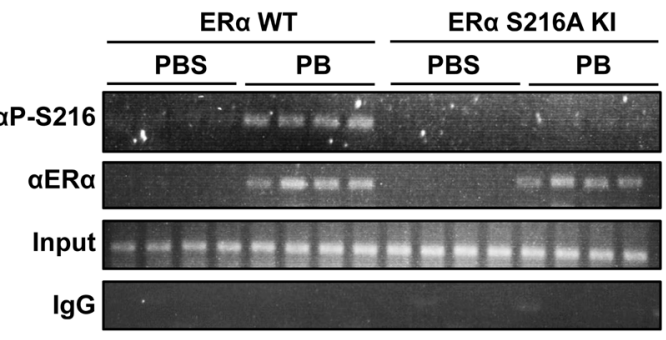

(f)

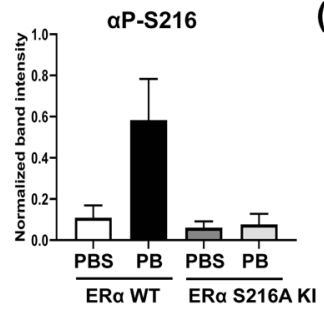

(g)



Figure 3. PB-induced binding of ER $\alpha$ phosphorylated at Ser216 to the Sult1e1 promoter in male mice. ChIP assays were employed to show ER $\alpha$ bindings to a proximal Sult1e1 promoter. (a) Schematic representation of a region that was amplified and primers that were used for PCR amplification. (b) Chromatins were prepared from livers of CAR WT and KO males treated with PB or PBS for $6 \mathrm{~h}$. And those were subjected to ChIP assays with either an ER $\alpha$ antibody or a P-S216 peptide antibody. Both of (c,d) show the quantification, which was normalized by input intensity, for P-ER $\alpha$ and $\mathrm{ER} \alpha$ respectively. The densitometry was performed by ImageJ. Kruskal-Wallis test and one-way ANOVA were used as statistical analyses, and $p$-values are 0.0004 and $<0.0001$ respectively. (e) Chromatins were prepared from livers of ER $\alpha$ and KI males treated with PB or PBS for $6 \mathrm{~h}$. And those chromatins were subjected to ChIP assays with either an ER $\alpha$ antibody or a P-S216 peptide antibody. Rabbit IgG was used as a negative control. Both of $(\mathbf{f}, \mathbf{g})$ present the quantifying data from ER $\alpha$ and KI males, which was normalized by input intensity, for P-ER $\alpha$ and ER $\alpha$ respectively. The densitometry was performed by ImageJ. Kruskal-Wallis test and one-way ANOVA were used as statistical analyses, and $p$-values are 0.0064 and $<0.0001$ respectively. All data are presented as means \pm S.D. of values of individual mice.

probe. Subsequently, coimmunoprecipitation assays were employed to examine interactions between CAR and ER $\alpha$. Flag-tagged CAR was co-expressed with EYFP-tagged ER $\alpha$ WT, ER $\alpha$ S216A or ER $\alpha$ S216D in Huh7 cells in the presence of $10 \mathrm{nM} 17 \beta$-estradiol. Precipitates formed by an anti-GFP antibody were analyzed by western blot using an anti-Flag antibody (Fig. 4c). CAR was effectively co-precipitated with ER $\alpha$ S216D, indicating that CAR forms a strong complex with phosphorylated ER $\alpha$ (Fig. 4c). In the absence of estrogen, this coprecipitation was not observed (data not shown). A 3D model of ER $\alpha$ homodimer interacting with CAR-RXR $\alpha$ heterodimer was created based on the homodimer of CAR. (Fig. 4d). This nuclear receptor heterotetramer may comprise a complex which regulates the expression of Sult1e1 gene.

SULT1E1 expression in diabetic livers. The C57BL/6J-derived Akita mice inherit the mutated insulin 1 gene and are used as an animal model for type 1 diabetes. CYP2B10 mRNA levels were up-regulated and CAR spontaneously accumulated in the nucleus in Akita males compared with those in C57BL/6J mice (Fig. 5a,b and Supplement Fig. 4). Levels of SULT1E1 mRNA were also up-regulated in the liver of Akita relative to those in C57BL/6J and CAR KO mice (Fig. 5c). To examine whether CAR regulated the expression of SULT1E1 in Akita, the Car gene was deleted from Akita by crossing Akita with CAR KO mice. The up-regulation of the basal of SULT1E1 mRNA expressions was no longer detected in Akita/CAR KO mice (Fig. 5c). ChIP assays were performed to examine ER $\alpha$ binding to the Sult1e1 promoter (Fig. 5d-f, and Supplement Fig. 5). ER $\alpha$ was only found with Akita, but with neither C57BL/6J, CAR KO nor Akita/CAR KO mice. Moreover, this ER $\alpha$ was phosphorylated at Ser216. Thus, the CAR-phosphorylated ER $\alpha$ signal regulated the promoter activation in Akita livers. Similar, the up-regulation of CYP2B10 mRNA and promoter binding of phosphorylated ER $\alpha$ were also observed in the livers of $o b / o b$ mice, an animal model of type 2 diabetes (Supplement Fig. 6).

$E R \alpha$ interactions with ROR $\alpha . \quad R O R \alpha$ repressed the Sult1e1 gene by binding its proximal promoter in mouse livers. In response to $\mathrm{PB}, \mathrm{ROR} \alpha$ was phosphorylated at Ser100, remaining on the promoter and co-activating it in CAR WT but not CAR KO mice ${ }^{19}$. In order to examine as to how ER $\alpha$ played a role in this regulation of ROR $\alpha$ ChIP assays were employed using a phospho-Ser100 peptide antibody and ER $\alpha$ KI mice. As observed in our previous work ${ }^{19}$, ROR $\alpha$ was found to bind the promoter before PB treatment in the liver of ER $\alpha$ 
(a)

${ }^{-126}$ GAGTGAGCAaactTGACCTTAT-105

(b)

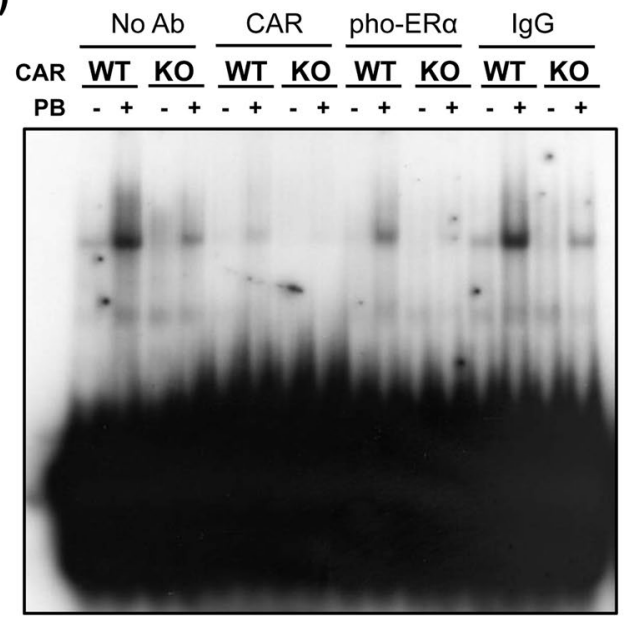

(c)

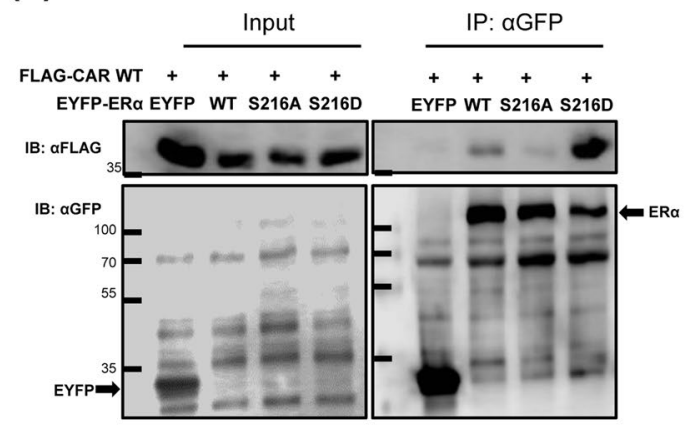

(d)

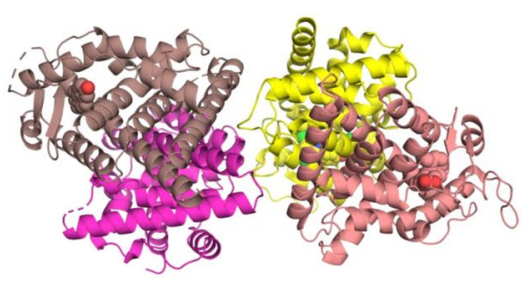

Figure 4. Interactions between CAR and phosphorylated ER $\alpha$. (a) The DR4 sequence was used as a probe for gel shift assays. (b) ${ }^{32} \mathrm{P}$-labeled double stranded probe was mixed with nuclear extracts prepared from mouse livers as indicated in the figure. For super shifts, CAR or phosphorylated ER $\alpha$ antibody was added to a mixture of probe and nuclear extract as indicated in the figure. (c) FLAG-tagged CAR was co-expressed with either EYFP-tagged ER $\alpha$ WT, ER $\alpha$ S216A, and ER $\alpha$ S216D in Huh7 cells in the presence of $10 \mathrm{nM} 17 \beta$-estradiol for $24 \mathrm{~h}$. Whole cell lysates were isolated and precipitated with $\alpha$ GFP-resin, eluted proteins from which were loaded on a SDS-PAGE gel and subjected to staining with an $\alpha$ FLAG antibody. Full-length gel images are described as Supplement Fig. 3. (d) 3D model of the hypothetical heterotetramer between an ER $\alpha$ homodimer (monomers in brown and magenta) and the CAR/RXR $\alpha$ heterodimer (CAR in yellow and RXR $\alpha$ in ash-rose). In this model one surface of CAR interacts with $\mathrm{RXR} \alpha$, while another surface interacts with an ER $\alpha$ subunit. Ligands (17 $\beta$-estradiol $(\mathrm{ER} \alpha)$, 9-cis-retinoic acid $(\mathrm{RXR} \alpha)$, 3,5-dichloro-2-(4-[(3,5-dichloropyridin-2-yl)oxy]phenoxy) pyridine (CAR)) are shown with atoms in spheres (oxygen in red, nitrogen in blue and chlorine in green, carbon atoms are colored as protein the ligands are bound to). This nuclear receptor tetramer may comprise a complex which regulates the expression of Sult1e1 gene. A description of how the model tetramer was created can be found in the Methods.

KI mice (Figs. 6a,c, and Supplement Fig. 7). While ROR $\alpha$ became phosphorylated at Ser100 in ER $\alpha$ KI WT mice, this phosphorylation was not observed in ER $\alpha$ KI mice (Fig. 6a,b, and Supplement Fig. 7). It was appeared that $\mathrm{ROR} \alpha$ phosphorylation required $\mathrm{ER} \alpha$ to be phosphorylated on the promoter. Moreover, $\mathrm{ER} \alpha$ and $\mathrm{ROR} \alpha$ may have interacted when both were phosphorylated. Consistent with notion, Co-IP assays showed that ER $\alpha$ S216D and $\mathrm{ROR} \alpha \mathrm{S} 100 \mathrm{D}$ were most effectively co-precipitated (Fig. 6d and Supplement Fig. 8).

\section{Discussion}

Nuclear receptors have the conserved phosphorylation motif within their DNA binding domains ${ }^{16}$. Phosphorylation of this motif enables nuclear receptors to interact among each other, thereby integrating their functions. Mouse ER $\alpha$ has this motif at Ser216 23 , which becomes phosphorylated on the Sult1e1 promoter in PB-treated and diabetic mouse livers. CAR recruits ER $\alpha$ onto the Sult1e1 promoter for subsequent phosphorylation of Ser216, thereby strengthening its interaction with ER $\alpha$ and activating the promoter. Thus, phosphorylation enables CAR to communicate with $\mathrm{ER} \alpha$ and integrates it into CAR-mediated activation of the gene.

CAR forms a heterodimer with RXR $\alpha$ through a well-known B dimer interface and is expected to utilize the A dimer interface to interact with $\mathrm{ER} \alpha$ (Fig. 7). ER $\alpha$ forms a homodimer through its B surfaces in the X-ray crystal structure $^{25}$, leaving A surfaces of both subunits to interact with another nuclear receptor such as CAR. In this model of interactions, CAR from the RXR $\alpha$-CAR heterodimer and one monomer of the ER $\alpha$ homodimer interact through their A surfaces (Fig. 4d). CAR initiates formation of this complex on the Sult1e1 promoter before ER $\alpha$ is phosphorylated. Whereas this complex with non-phosphorylated ER $\alpha$ formed in ER $\alpha$ S216A KI mice, the Sult1e1 gene was not activated, indicating that it is an inactive transcription complex. Phosphorylation of Ser216 occurs subsequent to formation of this inactive complex on the promoter, converting this inactive form to an active transcription complex. In fact, our Co-IP experiment showed that that the phosphorylation greatly enhances interactions between CAR and ER $\alpha$, supporting this notion. The uniqueness of this mechanism is that whole reaction processes from complex formation to phosphorylation and to activation undergo sequentially on the promoter, which enables CAR and ER $\alpha$ to target the Sult1e1 promoter and regulate it specifically and effectively. 
(a)

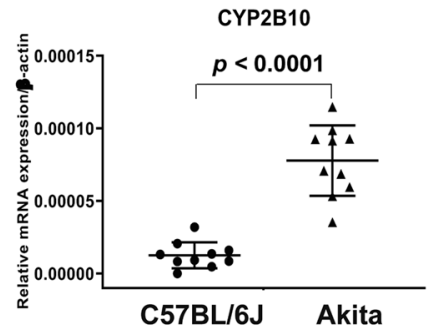

(b)

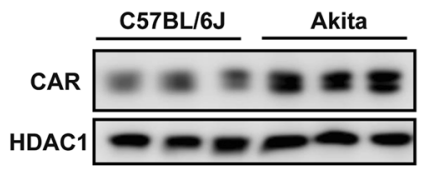

(c)

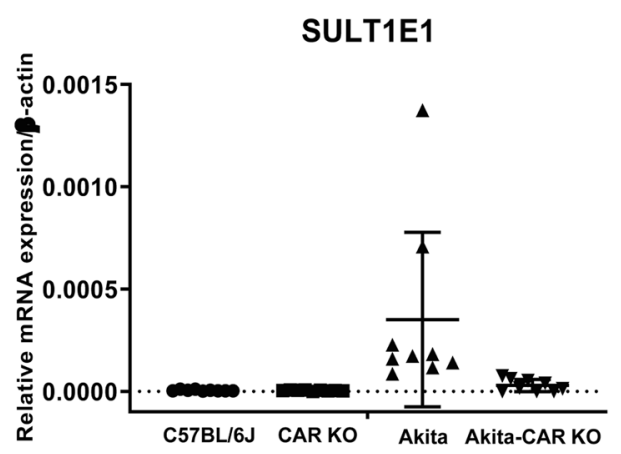

(d)

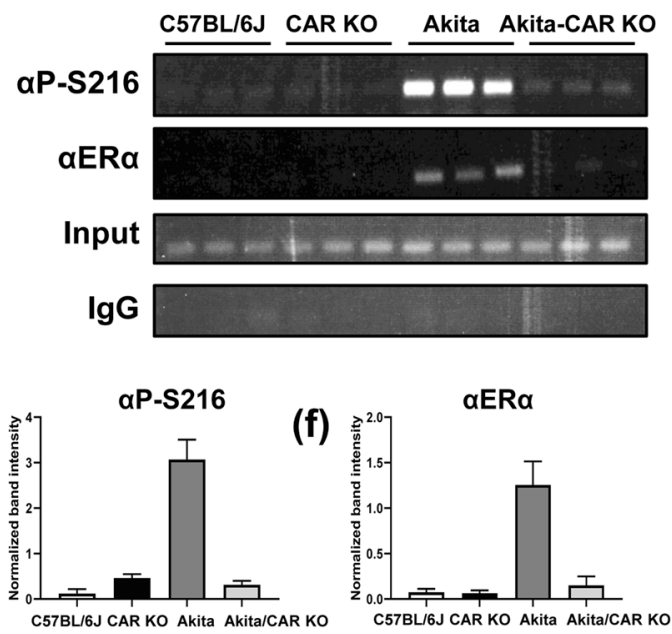

Figure 5. Hepatic SULT1E1 expression in Akita-CAR KO males. (a) Hepatic RNAs were prepared from C57BL/6J $(N=10)$ and Akita $(N=10)$ males. CYP2B10 mRNA, the classic CAR target showed the higher expression in Akita compared to C57BL/6J. Data set was analyzed by a Student's $t$-test, and $p$-value is lower than 0.0001. (b) Nuclear extracts were separately prepared form livers of C57BL/6J $(N=3)$ and Akita $(N=3)$. The expression of CAR in nucleus was higher than that of C57BL/6J. (c) Hepatic RNAs were prepared from CAR WT $(N=9)$, CAR KO $(N=8)$, Akita $(N=9)$ and Akita-CAR KO $(N=6)$. Data set was analyzed by KruskalWallis test, and $p$-value is 0.0001 . (d) Chromatins were separately prepared from three livers of each of the above-mentioned groups for subsequent ChIP assays. Both of $(\mathbf{e}, \mathbf{f})$ presented the quantifying data, which were normalized by input intensity, for P-ER $\alpha$ and $\mathrm{ER} \alpha$ respectively. The densitometry was performed by ImageJ. All data are presented as means \pm S.D. of values of individual mice and one-way ANOVA was used as a statistical analysis. Each $p$-value of both groups is lower than 0.0001 .

CAR was previously shown to form a complex with ROR $\alpha$ on the Sult1e1 promoter in mouse livers in response to $\mathrm{PB}$ treatment ${ }^{19}$. Upon treatment, $\mathrm{ROR} \alpha$, which repressed the promoter, became phosphorylated at Ser100, the corresponding conserved phosphorylation motif within the DBD. This phosphorylation converted ROR $\alpha$ from a corepressor to co-activator for CAR to activate the promoter. Therefore, CAR appears to integrate ROR $\alpha$ in addition to ER $\alpha$ through phosphorylation of their conserved motifs. Our present study found that this conversion did not occur in $\mathrm{ER} \alpha \mathrm{KI}$ mice and, that $\mathrm{ER} \alpha$ and ROR $\alpha$ strongly interacted when both were phosphorylated. These observations are consistent with the hypothesis that phosphorylated ER $\alpha$ interacts with ROR $\alpha$ for subsequent phosphorylation, thereby converting ROR $\alpha$ to an activator. For this end, since phosphorylated ER $\alpha$ interacted with CAR and phosphorylated ROR $\alpha$, a phosphorylated ER $\alpha$ homodimer may sandwich CAR and phosphorylated ROR $\alpha$. The molecular mechanism of how these three nuclear receptors coordinate to regulate the Sult1e1 gene remains to be investigated in the future.

PB treatment is known to decrease blood glucose levels and improve insulin sensitivity in epileptic patients ${ }^{26}$. Similar to insulin but via different mechanism, PB represses hepatic gluconeogenesis, causing beneficial effects against the development and progression of type 2 diabetes $^{27}$. Insulin excludes FOXO1 from the nucleus while PB enables CAR to directly interact with and inactivate FOXO1, both resulting in the repression of FOXO1-mediated activation of gluconeogenic genes. On the other hand, insulin antagonizes PB to stimulate ERK1/2 signal, which retains inactive CAR in the cytoplasm. When insulin actions are deteriorated in diabetic livers, CAR spontaneously accumulates in the nucleus. Either by $\mathrm{PB}$ or spontaneous activation, CAR recruits phosphorylated ER $\alpha$ to activate the Sult1e1 gene. Therefore, these observations a consistent with the notion that an increase of SULT1E1 enzyme produces beneficial responses against diabetes. Estrogen is an anti-inflammatory hormone ${ }^{28,29}$ which causes both beneficial and toxic effects ${ }^{30}$, SULT1E1 may balance estrogen effects by metabolizing estrogen. Ablation of the Sult1e1 gene increased susceptibility to LPS-induced sepsis in mice ${ }^{11}$. Moreover, hepatic diabetic phenotype was worsened by ablation of the Sult1e1 gene in male $o b / o b$ mice $^{12}$. Future studies may establish the 
(a)

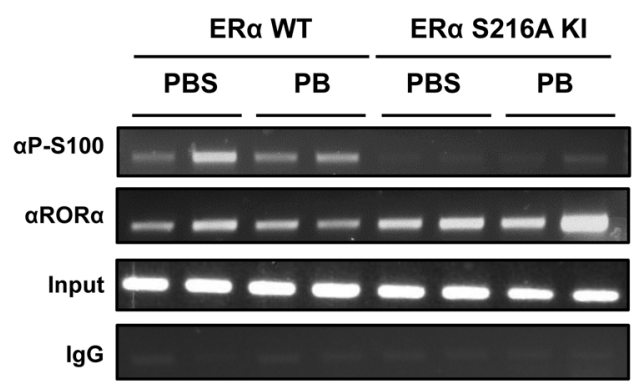

(d)

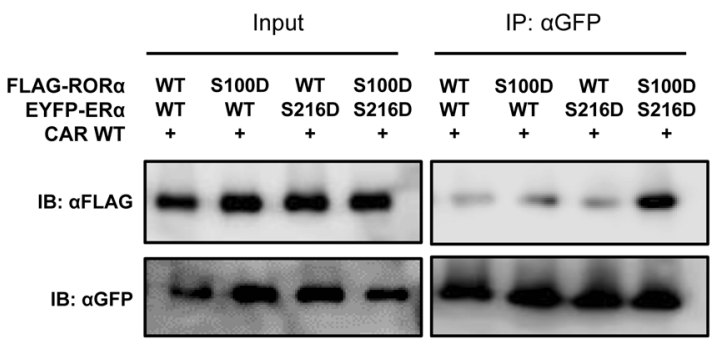

(b)

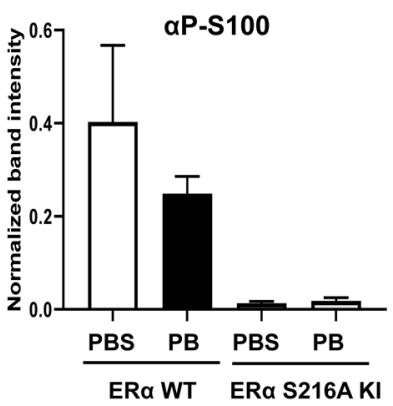

(c)

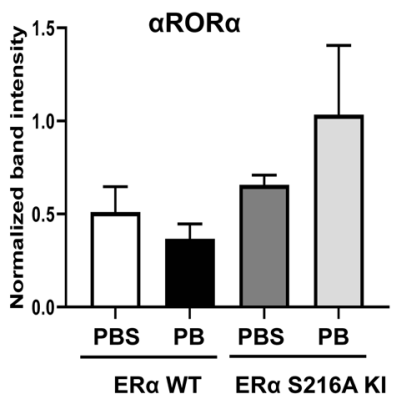

Figure 6. Non-phosphorylated ER $\alpha$ is not bound to the Sult1e1 promoter in male mice with P-ROR $\alpha$. ChIP assays were applied to show ROR $\alpha$ bindings to a proximal Sult1e1 promoter. (a) Chromatins were prepared from livers of ER $\alpha$ WT and KI males which were subjected to ChIP assays with either an ROR $\alpha$ antibody or a P-S100 peptide antibody. Both of $(\mathbf{b}, \mathbf{c})$ indicate the data quantification, which was normalized by input intensity, for P-ROR $\alpha$ and ROR $\alpha$ respectively. The assay was examined by ImageJ, and one-way ANOVA were used as statistical analyses, and $p$-values are 0.0247 and 0.1080 respectively. (d) V5-CAR WT (no tag) was co-expressed with FLAG-tagged ROR $\alpha$ WT, ROR $\alpha$ S100D, EYFP-tagged ER $\alpha$ WT, and ER $\alpha$ S216D in Huh7 cells. Whole cell lysates were isolated and precipitated with $\alpha$ GFP-resin, and eluted proteins were loaded on a SDS-PAGE gel and subjected to staining with an $\alpha$ GFP- or $\alpha$ FLAG antibody.

CAR-phosphorylated ER $\alpha$ pathway as the signal pathway that regulates active estrogen levels to counter pathophysiological developments such as diabetes.

In conclusion, CAR is the principle transcription factor that activates the Sult1e1 gene by recruiting ER $\alpha$ phosphorylated at Ser216 to activate the Sult1e1 gene. Ser216, the conserved phosphorylation motif within the $\mathrm{DBD}$, is utilized by CAR to communicate with ER $\alpha$, integrating it into CAR-mediated gene's activation. Ser216 is conserved in the majority of nuclear receptors such as Ser100 of ROR $\alpha$; as CAR does with ER $\alpha$ and also ROR $\alpha$, nuclear receptors may communicate among themselves through the conserved motif to increase and diverge their actions.

This phosphorylation-medicated communication of CAR with ER $\alpha$ is also utilized to activate the Sult1e1 gene in diabetic livers, possibly allowing us to develop drugs that target phosphorylated ER $\alpha$ for clinical therapy.

\section{Methods}

Reagents and plasmids. Polyclonal antibodies for SULT1E1 (12522-1-AP) and $\alpha$-tubulin (\#2144S) were manufactured by ProteinTech (Rosemont, IL, USA) and Cell Signaling Technology (Beverly, MA, USA), respectively. Monoclonal antibodies against ER $\alpha$, ab32063 and sc-543 were obtained from Abcam Plc. (Cambridge, UK) and Santa Cruz Biotech, Inc. (Dallas, TX, USA), respectively. Each monoclonal antibody against CAR (PPN4111-00) and ROR $\alpha$ (PP-H3910-00) was produced by Perseus Proteomics (Tokyo, Japan). Polyclonal antibodies against RXR (sc-774), HDAC1 (sc-6298), normal rabbit IgG (sc-2027), each secondary antibody of mouse (sc-2314) and goat (sc-2020) were purchased from Santa Cruz Biotech, Inc. (Dallas, TX, USA). An antibody for GFP-HRP (ab6663) was obtained from Abcam (Cambridge, UK). A HRP-conjugated anti-FLAG M2 (A8592) was from Sigma-Aldrich (St. Louis, MO, USA). Anti-phospho-Ser216 peptide antibodies ( $\alpha$ P-Ser216) for mER $\alpha$ and hROR $\alpha(\alpha$ P-Ser100) were generated by GenScript (Piscataway, NJ, USA). An anti-phospho-Ser212 peptide antibody for hER $\alpha$ was produced by Anaspec (Fremont, CA, USA). A HRP-conjugated secondary antibody of rabbit (65-6120) was purchased from Thermo Fisher Scientific (Waltham, MA, USA). A FuGENE 6 transfection reagent (E2691) was from Promega Corporation (Madison, WI, USA). Bio-Rad Protein Assay reagent was from Bio-Rad (Hercules, CA, USA). WesternBright ECL and Sirius HRP substrate were from Advansta (San Jose, CA, USA). Restriction enzymes were from New England Biolabs (Ipswich, MA, USA), and the ChIP IT Express kit was manufactured from Active Motif (Carlsbad, CA, USA). pGL3 vectors harboring mouse Sult1e1 promoter were constructed as described in our previous study ${ }^{31}$. All constructs were verified by nucleotide sequencing. 


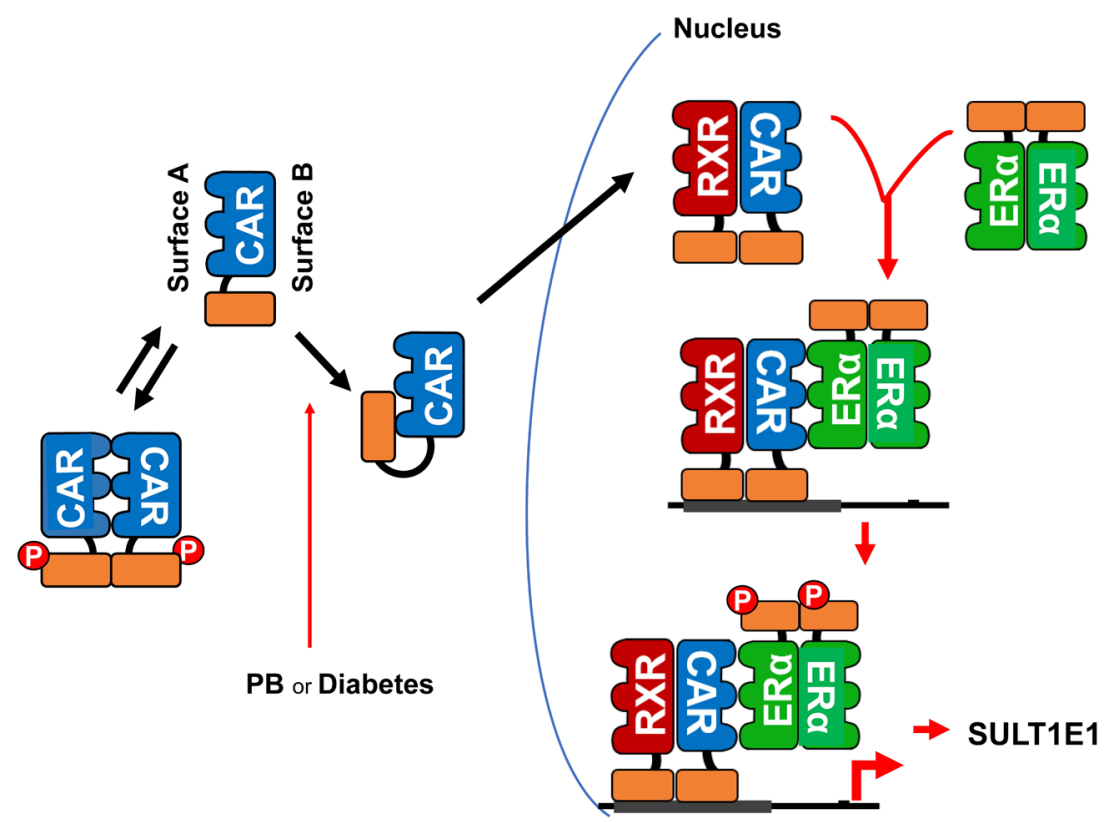

Figure 7. Schematic depiction of the CAR-ER $\alpha$ communication mechanism. CAR phosphorylated at Thr38 forms a homodimer through surface $\mathrm{A}$ and remains inactive in the cytoplasm ${ }^{14,17}$. In response to PB, Thr 38 is dephosphorylated and non-phosphorylated CAR homodimer dissociates, allowing the interaction between the DBD and LBD to translocate into the nucleus ${ }^{17,18}$. In the nucleus, CAR utilizes its surface $B$ to form an $\mathrm{RXR} \alpha-\mathrm{CAR}$ heterodimer. ER $\alpha$ dimerizes through B surfaces upon estrogen binding. Subsequently, RXR $\alpha$-CAR heterodimer recruits ER $\alpha$ homodimer to the Sulte1 promoter by between the heterodimer-bound CAR and homodimer-bound ER $\alpha$ via their A surfaces. While phosphorylated ER $\alpha$ is unable to directly bind DNA, its homodimer sandwiches RXR $\alpha$-CAR heterodimer and phosphorylated $\mathrm{ROR} \alpha$, resulting in an activation of the promoter.

Animals. ER $\alpha$ WT and Ex3-ER $\alpha$ KO mice were kindly provided by Drs. Sylvia Hewitt and Kenneth Korach at NIEHS ${ }^{32}$. ER $\alpha$ S216A KI mice were generated by the core at NIEHS, and they are fertile. More details for characterization of this mouse strain will be published elsewhere. Briefly, DNA fragments of the Esr1 gene of C57BL/6J genes were mutated and injected ES cells from 129 mice. Brothers and sisters generated heterozygous were crossed, form which $\mathrm{ER} \alpha \mathrm{WT}$ and $\mathrm{ER} \alpha \mathrm{KI}$ lines were established. Both males and males are fertile. CAR $\mathrm{KO}$ mice in C57BL/6J background were produced in house. Akita and $o b / o b$ mice were purchased from Jackson Laboratory. Akita heterozygotes were crossed with CAR KO mice in house and genotyped using proper probes produced by Transnetyx (Cordova, TN, USA), to ablate CAR (Akita-CAR KO). PB (100 mg/kg body weight) in PBS or PBS was intraperitoneally injected into 8- to 15-week-old male mice for 6 or $24 \mathrm{~h}$. Each mouse was maintained under the standard condition at the NIEHS. Animal experiments were conducted per protocols approved by the Animal Care and Use Committee (ACUC) at NIEHS/NIH. All methods and procedures were performed in accordance with the Public Health Service Policy with humane examinations.

Extraction of RNA and quantitative real-time PCR (RT-PCR). Total RNAs from mouse livers were isolated using TRIzol reagent (Invitrogen, Carlsbad, CA, USA) according to the manufacturer's instructions. All of isolated RNAs were quantified and certified using NanoPhotometer (Implen GmbH, München, Germany). Each cDNA was synthesized with High Capacity cDNA Reverse Transcription Kit (Thermo Fisher Scientific, Waltham, MA, USA) adding $2 \mu \mathrm{g}$ of total RNA to the reaction mixture, and the reaction mixtures were incubated at $37^{\circ} \mathrm{C}$ for $2 \mathrm{~h}$. Each synthesized cDNA was quantified and certified using Beckman DU 640 spectrophotometer (Beckman Coulter Inc., Brea, CA, USA) by measuring the absorbance at $260 \mathrm{~nm}$ and $280 \mathrm{~nm}$. Taqman probes were used as Mm00499178_m1, Mm00456591_m1 and REF4352663 for SULT1E1, CYP2B10 and $\beta$-actin, respectively. qPCR was performed with the CFX96 Touch Real-Time PCR Detection System (Bio-Rad Laboratories Inc., Hercules, CA, USA). Each value was derived from the comparative CT method which compared the $C_{\mathrm{t}}$ value of one target gene to reference gene using the $2^{-\Delta \Delta C t}$ formula according to the manufacturer's guideline. $\Delta C_{\mathrm{t}}$ indicates the differences in threshold cycles for target and reference $\left(C_{\mathrm{t}, \text { target }}-C_{\mathrm{t}, \text { reference }}\right)$, and $\Delta \Delta C_{\mathrm{t}}$ represents the relative change in these differences between the target and reference $\left(\Delta C_{\mathrm{t}, \text { target }}-\Delta C_{\mathrm{t}, \text { reference }}\right)$. Therefore, the expression of target, normalized to a house keeping gene, was given by $2^{-\Delta \Delta C t}$.

Extraction of protein and western blot. The cytosolic and nuclear proteins from the mouse livers were prepared by NE-PER nuclear and cytoplasmic extraction reagents (78835, ThermoFisher Scientific) based on the manufacturer's instruction. About 20-50 mg liver was cut into small pieces and washed with PBS. The tissue pellet was homogenized by a Dounce homogenizer in the $500 \mu \mathrm{L}$ volume of CER I reagent. Each tube was vortexed vigorously for $15 \mathrm{sec}$ to fully suspend the pellet, and incubated on ice for $10 \mathrm{~min}$. Then, the $27.5 \mu \mathrm{L}$ of pre-chilled 
CER II reagent was added into a tube, mixed thoroughly, incubated on ice for $1 \mathrm{~min}$ and centrifuged for $5 \mathrm{~min}$ at $12,000 \times g$. The supernatant containing cytoplasmic extract was transferred to a pre-chilled tube, and the remain insoluble fraction was suspended into the $250 \mu \mathrm{L}$ of NER reagent. After $15 \mathrm{sec}$ of thorough mixing, a tube was placed on ice and continued vortexing for $15 \mathrm{sec}$ every $10 \mathrm{~min}$. After a total of $40 \mathrm{~min}$, all of samples were centrifuged at $12,000 \times g$ for $10 \mathrm{~min}$, and the supernatant fraction which contained nuclear extract was transferred to a clean pre-chilled tube. All prepared proteins were stored at $-80^{\circ} \mathrm{C}$ and thawed in ice before using. Huh7 cells lysates were extracted using IP buffer containing $20 \mathrm{mM}$ Tris- $\mathrm{HCl}$ (pH 7.5), $250 \mathrm{mM} \mathrm{NaCl}, 1 \%$ (v/v) Triton-X 100, $10 \%(\mathrm{v} / \mathrm{v})$ glycerol, protease inhibitors and phosphatase inhibitors. Each protein concentration was estimated using Bio-Rad protein assay dye reagent. Each sample was separated into a 10\% SDS-PAGE gel, and separated proteins were transferred onto a PVDF membrane (GE Healthcare, Little Chalfont, UK). The nonspecific proteins were blocked using $5 \%(\mathrm{w} / \mathrm{v})$ skim milk or $5 \%(\mathrm{w} / \mathrm{v})$ BSA in tris-buffered saline containing $0.1 \%(\mathrm{v} / \mathrm{v})$ Tween 20 (T-TBS). A WesternBright ECL or Sirius kit (Advansta Inc., San Jose, CA, USA) detected HRP substrates, and results were visualized by a C-DiGit Chemiluminescent Western Blot Scanner (LI-COR, Inc., Lincoln, NE, USA). Quantitative densitometry was determined using ImageJ 1.52a, Java 1.8.0_112 version (NIH, Bethesda, $\mathrm{MD}, \mathrm{USA})$. Values are means \pm S.D relative to each described loading control.

Chromatin immunoprecipitation assay (ChIP). About $200 \mathrm{mg}$ liver was minced and incubated in a $1 \%(\mathrm{v} / \mathrm{v})$ formaldehyde for $10 \mathrm{~min}$ followed by a glycine incubation for $5 \mathrm{~min}$ at room temperature before homogenization ${ }^{19}$. Each suspension which contained nuclear protein was obtained by filtering homogenates through a $100 \mu \mathrm{m}$ of Falcon cell strainer (BD Biosciences, Bedford, MA, USA) ${ }^{19}$, incubated in the lysis buffer, and sonicated in the shearing buffer including $500 \mu \mathrm{M}$ of PMSF and PIC as manufacturer's guide line (Active motif). Immunoprecipitations were performed overnight with an ER $\alpha$ antibody or a phospho-ER $\alpha$ antibody respectively using protein $\mathrm{G}$ conjugated magnetic beads. The beads were washed with ChIP buffers, chromatins were eluted, and the cross-linking was reversed prior to PCR (38 cycles) amplification using primers targeting the proximal region $(-168 /+68)$ of mouse Sult1e1 promoter. The sequence of primer pairs is: forward primer 5'ACCCAAAGGGGAGAAACAGC-3', and reverse primer 5'-TCGAATGGCAGCACGATTCT-3'.

Electrophoretic mobility gel shit assay (EMSA). Gel mobility shift assays were performed as described in previous studies ${ }^{19,33}$. Briefly, annealed double-strand oligonucleotides were labelled with $\left[\alpha-{ }^{32} \mathrm{P}\right] \mathrm{dATP}$ by fill-in reaction using T4 polynucleotide kinase (PNK) to generate radioactive probes. For observing the supershifts, mixtures were incubated with $1 \mu \mathrm{g}$ of nuclear protein extracts and anti-phospho ER $\alpha$ or -CAR antibodies at room temperature for $10 \mathrm{~min}$. Nucleotide sequences used as probes are described in Fig. $4 \mathrm{a}$.

Cell culture and transfection. Huh7 (hepatocyte-derived carcinoma cell line) was purchased from the American Type Culture Collection (ATCC; Manassas, VA, USA). Dulbecco's modified eagle medium (DMEM; 11965-092) was manufactured by Gibco (Waltham, MA, USA). Fetal bovine serum (FBS; S11150) was produced by Atlanta Biologicals (Flowery Branch, GA, USA). Penicillin-streptomycin (P0781) and sodium pyruvate (S8636) were purchased from Sigma-Aldrich (St. Louis, MO, USA). Huh7 cells were cultured in DMEM which supplemented with $10 \% \mathrm{FBS}(\mathrm{v} / \mathrm{v}), 1 \mathrm{mM}$ sodium pyruvate, $100 \mathrm{units} / \mathrm{mL}$ penicillin, and $100 \mu \mathrm{g} / \mathrm{mL}$ streptomycin at $37^{\circ} \mathrm{C}$ containing $5 \% \mathrm{CO}_{2}$ in the humidified atmosphere. Transfections with each plasmid were performed using FuGENE 6 per the manufacturer's protocols. For each well, $1 \times 10^{5} \mathrm{Huh} 7$ cells were distributed into a $100 \mathrm{~mm}$ culture dish and incubated at $37^{\circ} \mathrm{C}$ for $24 \mathrm{~h}$. The transfection mixture was prepared with containing $5 \mu \mathrm{g}$ of each cDNA, $25 \mu \mathrm{L}$ of FuGENE 6 and $10 \mathrm{~mL}$ Opti-MEM reduced serum medium (31985-070, Gibco) at room temperature for $15 \mathrm{~min}$. When the cells turned into adhesive, the growth medium was replaced with the transfection mixture and cells were incubated for additional $24 \mathrm{~h}$ at $37^{\circ} \mathrm{C}$.

Co-immunoprecipitation (Co-IP). Huh7 cells transfected with indicated plasmids for $24 \mathrm{~h}$ were lysed in immunoprecipitation (IP) buffer containing $20 \mathrm{mM}$ Tris- $\mathrm{HCl}$ (pH 7.5), $250 \mathrm{mM} \mathrm{NaCl}, 1 \%$ (v/v) Triton-X $100,10 \%(\mathrm{v} / \mathrm{v})$ glycerol, protease and phosphatase inhibitor cocktails (78442, ThermoFisher Scientific). Each lysate was collected by centrifugation and sonicated. The collected supernatants were incubated with anti-GFP antibody-conjugated agarose at $4^{\circ} \mathrm{C}$ for overnight. Resins were washed three times with the IP buffer, subjected to SDS-PAGE for western blot analysis.

Model displays a hypothetical heterotetramer of an ER $\alpha$ homodimer with a CAR/RXR $\alpha$ heterodimer. The relative orientation of the ER $\alpha$ homodimer to the CAR/RXR $\alpha$ heterodimer was determined by superimposing the CAR from the CAR/RXR $\alpha$ heterodimer (PDBid:1XLS; CAR in yellow/RXR $\alpha$ in ash-rose Fig. 4d) onto molecule A of the CAR homodimer (PDBid:1XNX; not shown) while a monomer from the ER $\alpha$ homodimer (PDBid:1ERE; magenta/brown) was superimposed onto molecule B of the CAR homodimer (PDBid:1XNX; not shown). Ligands from the respective structures are shown in spheres. Superpositions and graphics were performed using the PyMOL Molecular Graphics System, version 2.0 Schrödinger, LLC. (New York, NY, USA).

Data analysis. Data were analyzed by D’Agostino-Pearson test for evaluating normality. Data of two groups which meet the assumption of normality were analyzed by Student's $t$-test. Data of multiple groups which meet the assumption of normality were analyzed by one-way ANOVA test, and which do not meet the assumption were analyzed by Kruskal-Wallis test. All statistical analyses and graphical visualizations were conducted by Prism 8.2.1 (GraphPad Software, San Diego, CA, USA). All data are presented as means \pm S.D. of each independent value. $P$-values $<0.05$ were regarded as statistically significant. 


\section{Data availability}

The data sets generated during and/or analyzed in the current study will be made available to the research community upon requests.

Received: 9 December 2019; Accepted: 28 February 2020;

Published online: 19 March 2020

\section{References}

1. Paterni, I., Granchi, C., Katzenellenbogen, J. A. \& Minutolo, F. Estrogen receptors alpha (ERalpha) and beta (ERbeta): subtypeselective ligands and clinical potential. Steroids 90, 13-29, https://doi.org/10.1016/j.steroids.2014.06.012 (2014).

2. Yasar, P., Ayaz, G., User, S. D., Gupur, G. \& Muyan, M. Molecular mechanism of estrogen-estrogen receptor signaling. Reprod. Med. Biol. 16, 4-20, https://doi.org/10.1002/rmb2.12006 (2017).

3. Svenson, J. L., EuDaly, J., Ruiz, P., Korach, K. S. \& Gilkeson, G. S. Impact of estrogen receptor deficiency on disease expression in the NZM2410 lupus prone mouse. Clin. Immunol. 128, 259-268, https://doi.org/10.1016/j.clim.2008.03.508 (2008).

4. Song, W. C., Qian, Y., Sun, X. \& Negishi, M. Cellular localization and regulation of expression of testicular estrogen sulfotransferase. Endocrinol. 138, 5006-5012, https://doi.org/10.1210/endo.138.11.5512 (1997).

5. Kakuta, Y. et al. Mouse steroid sulfotransferases: substrate specificity and preliminary X-ray crystallographic analysis. Biochem. Pharmacol. 55, 313-317, https://doi.org/10.1016/s0006-2952(97)00465-6 (1998).

6. Kakuta, Y., Pedersen, L. G., Pedersen, L. C. \& Negishi, M. Conserved structural motifs in the sulfotransferase family. Trends Biochem. Sci. 23, 129-130 (1998).

7. Kakuta, Y., Petrotchenko, E. V., Pedersen, L. C. \& Negishi, M. The sulfuryl transfer mechanism. Crystal structure of a vanadate complex of estrogen sulfotransferase and mutational analysis. J. Biol. Chem. 273, 27325-27330, https://doi.org/10.1074/ jbc.273.42.27325 (1998).

8. Sueyoshi, T. et al. A role of Lys614 in the sulfotransferase activity of human heparan sulfate $\mathrm{N}$-deacetylase/N-sulfotransferase. FEBS Lett. 433, 211-214, https://doi.org/10.1016/s0014-5793(98)00913-2 (1998).

9. Petrotchenko, E. V., Doerflein, M. E., Kakuta, Y., Pedersen, L. C. \& Negishi, M. Substrate gating confers steroid specificity to estrogen sulfotransferase. J. Biol. Chem. 274, 30019-30022, https://doi.org/10.1074/jbc.274.42.30019 (1999).

10. Sueyoshi, T. et al. Garlic extract diallyl sulfide (DAS) activates nuclear receptor CAR to induce the Sult1e1 gene in mouse liver. PLoS One 6, e21229, https://doi.org/10.1371/journal.pone.0021229 (2011).

11. Barbosa, A. C. S., Feng, Y., Yu, C., Huang, M. \& Xie, W. Estrogen sulfotransferase in the metabolism of estrogenic drugs and in the pathogenesis of diseases. Expert. Opin. Drug. Metab. Toxicol. 15, 329-339, https://doi.org/10.1080/17425255.2019.1588884 (2019).

12. Gao, J. et al. Sex-specific effect of estrogen sulfotransferase on mouse models of type 2 diabetes. Diabetes 61, 1543-1551, https://doi. org/10.2337/db11-1152 (2012).

13. Kodama, S., Koike, C., Negishi, M. \& Yamamoto, Y. Nuclear receptors CAR and PXR cross talk with FOXO1 to regulate genes that encode drug-metabolizing and gluconeogenic enzymes. Mol. Cell Biol. 24, 7931-7940, https://doi.org/10.1128/MCB.24.18.79317940.2004 (2004).

14. Mutoh, S. et al. Dephosphorylation of threonine 38 is required for nuclear translocation and activation of human xenobiotic receptor CAR (NR113). J. Biol. Chem. 284, 34785-34792, https://doi.org/10.1074/jbc.M109.048108 (2009).

15. Yasujima, T., Saito, K., Moore, R. \& Negishi, M. Phenobarbital and Insulin Reciprocate Activation of the Nuclear Receptor Constitutive Androstane Receptor through the Insulin Receptor. J. Pharmacol. Exp. Ther. 357, 367-374, https://doi.org/10.1124/ jpet.116.232140 (2016).

16. Negishi, M. Phenobarbital Meets Phosphorylation of Nuclear Receptors. Drug. Metab. Dispos. 45, 532-539, https://doi.org/10.1124/ dmd.116.074872 (2017).

17. Shizu, R. et al. Phosphorylated Nuclear Receptor CAR Forms a Homodimer To Repress Its Constitutive Activity for Ligand Activation. Mol Cell Biol 37, https://doi.org/10.1128/MCB.00649-16 (2017).

18. Shizu, R. et al. Interaction of the phosphorylated DNA-binding domain in nuclear receptor CAR with its ligand-binding domain regulates CAR activation. J. Biol. Chem. 293, 333-344, https://doi.org/10.1074/jbc.M117.806604 (2018).

19. Fashe, M., Hashiguchi, T., Yi, M., Moore, R. \& Negishi, M. Phenobarbital-induced phosphorylation converts nuclear receptor RORalpha from a repressor to an activator of the estrogen sulfotransferase gene Sult1el in mouse livers. FEBS Lett. 592, 2760-2768, https://doi.org/10.1002/1873-3468.13199 (2018).

20. Qiu, S. et al. Hepatic estrogen receptor alpha is critical for regulation of gluconeogenesis and lipid metabolism in males. Sci. Rep. 7, 1661, https://doi.org/10.1038/s41598-017-01937-4 (2017).

21. Gao, J., He, J., Zhai, Y., Wada, T. \& Xie, W. The constitutive androstane receptor is an anti-obesity nuclear receptor that improves insulin sensitivity. J. Biol. Chem. 284, 25984-25992, https://doi.org/10.1074/jbc.M109.016808 (2009).

22. Shindo, S., Sakuma, T., Negishi, M. \& Squires, J. Phosphorylation of serine 212 confers novel activity to human estrogen receptor alpha. Steroids 77, 448-453, https://doi.org/10.1016/j.steroids.2012.01.001 (2012).

23. Shindo, S., Moore, R., Flake, G. \& Negishi, M. Serine 216 phosphorylation of estrogen receptor alpha in neutrophils: migration and infiltration into the mouse uterus. PLoS One 8, e84462, https://doi.org/10.1371/journal.pone.0084462 (2013).

24. Ueda, A. et al. Diverse roles of the nuclear orphan receptor CAR in regulating hepatic genes in response to phenobarbital. Mol. Pharmacol. 61, 1-6, https://doi.org/10.1124/mol.61.1.1 (2002).

25. Tanenbaum, D. M., Wang, Y., Williams, S. P. \& Sigler, P. B. Crystallographic comparison of the estrogen and progesterone receptor's ligand binding domains. Proc. Natl Acad. Sci. USA 95, 5998-6003, https://doi.org/10.1073/pnas.95.11.5998 (1998).

26. Lahtela, J. T., Sarkka, P. \& Sotaniemi, E. A. Phenobarbital treatment enhances insulin mediated glucose metabolism in man. Res. Commun. Chem. Pathol. Pharmacol. 44, 215-226 (1984).

27. Lahtela, J. T., Arranto, A. J. \& Sotaniemi, E. A. Enzyme inducers improve insulin sensitivity in non-insulin-dependent diabetic subjects. Diabetes 34, 911-916, https://doi.org/10.2337/diab.34.9.911 (1985).

28. Gruber, C. J., Tschugguel, W., Schneeberger, C. \& Huber, J. C. Production and actions of estrogens. N. Engl. J. Med. 346, 340-352, https://doi.org/10.1056/NEJMra000471 (2002).

29. Riggs, B. L. \& Hartmann, L. C. Selective estrogen-receptor modulators-mechanisms of action and application to clinical practice. $N$. Engl. J. Med. 348, 618-629, https://doi.org/10.1056/NEJMra022219 (2003).

30. Santen, R. J. \& Allred, D. C. The estrogen paradox. Nat. Clin. Pract. Endocrinol. Metab. 3, 496-497, https://doi.org/10.1038/ ncpendmet0535 (2007).

31. Kodama, S., Hosseinpour, F., Goldstein, J. A. \& Negishi, M. Liganded pregnane X receptor represses the human sulfotransferase SULT1E1 promoter through disrupting its chromatin structure. Nucleic Acids Res. 39, 8392-8403, https://doi.org/10.1093/nar/ gkr458 (2011).

32. Hewitt, S. C. et al. Biological and biochemical consequences of global deletion of exon 3 from the ER alpha gene. FASEB J. 24, 4660-4667, https://doi.org/10.1096/f.10-163428 (2010).

33. Ueda, H. \& Hirose, S. Defining the sequence recognized with BmFTZ-F1, a sequence specific DNA binding factor in the silkworm, Bombyx mori, as revealed by direct sequencing of bound oligonucleotides and gel mobility shift competition analysis. Nucleic Acids Res. 19, 3689-3693, https://doi.org/10.1093/nar/19.13.3689 (1991). 


\section{Acknowledgements}

ER $\alpha$ KO mice were kindly provided by Dr. Kenneth S. Korach (NIEHS). DNA sequence core lab at NIEHS also assisted us for preparing GFP-labelled resin. Also, a 3D structure of ER $\alpha$-CAR-RXR $\alpha$ was precisely modeled by Dr. Lars C. Pedersen (NIEHS). This study was supported by the Intramural Research Program of NIH, National Institute of Environmental Health Sciences Z01ES1005-01.

\section{Author contributions}

M.N. and M.Y. constructed the idea, wrote the manuscript and submit it. M.Y., M.F., S.A., R.M., and T.S. designed and performed the experimental procedures. M.Y. and S.A. analyzed the data and visualized it.

\section{Competing interests}

The authors declare no competing interests.

\section{Additional information}

Supplementary information is available for this paper at https://doi.org/10.1038/s41598-020-61767-9.

Correspondence and requests for materials should be addressed to M.N.

Reprints and permissions information is available at www.nature.com/reprints.

Publisher's note Springer Nature remains neutral with regard to jurisdictional claims in published maps and institutional affiliations.

(c) (i) Open Access This article is licensed under a Creative Commons Attribution 4.0 International License, which permits use, sharing, adaptation, distribution and reproduction in any medium or format, as long as you give appropriate credit to the original author(s) and the source, provide a link to the Creative Commons license, and indicate if changes were made. The images or other third party material in this article are included in the article's Creative Commons license, unless indicated otherwise in a credit line to the material. If material is not included in the article's Creative Commons license and your intended use is not permitted by statutory regulation or exceeds the permitted use, you will need to obtain permission directly from the copyright holder. To view a copy of this license, visit http://creativecommons.org/licenses/by/4.0/.

(C) The Author(s) 2020 